\title{
A Case Study of the Retrofitting of the Great Fish River Bridge
}

\author{
Nerave Moodley ${ }^{1, *}$, Graham Moore ${ }^{1}$, and David Wylie $^{1}$ \\ ${ }^{1}$ Mott MacDonald Africa (Pty) Ltd, 21 Aurora Drive Umhlanga, Durban, South Africa
}

\begin{abstract}
In developing countries and economies such as South Africa, retrofitting is a vital tool to maximise and extend the service life of existing infrastructure. The transportation sector plays a pivotal role in stimulating economic growth, and retrofitting existing bridges to meet the growing capacity needs of South Africa's roads supports continued economic growth and development. This paper outlines the technical and practical challenges encountered and the solutions developed by the design team to retrofit the existing 215m long, 9-span, Great Fish River Bridge in the Eastern Cape of South Africa. These challenges included jacking up the existing bridge under traffic loading to replace 108 existing bearings and erecting $32.5 \mathrm{t}$ precast beams at heights of $10.5 \mathrm{~m}$ above a major river whilst accommodating high volumes of traffic on a busy National road.
\end{abstract}

\section{Introduction}

The existing $215 \mathrm{~m}$ long, 9-span, bridge was constructed in 1959 and spans the width of the river valley. The superstructure is $10.5 \mathrm{~m}$ above the river and is located at km 103.5 along Section 13 of the N2 between Peddie and Grahamstown in the Eastern Cape of South Africa. It is constructed on an S-bend curve with supports at skews varying between $25^{\circ}$ and $30^{\circ}$. The existing superstructure comprises prestressed, precast I-beams with an in-situ deck slab, simply supported on concrete hinge bearings resting on reinforced concrete wall-type piers and reinforced concrete abutments. The South African National Road Agency Limited (SANRAL), as the owner of the structure commissioned an upgrade to Section 13 of the $\mathrm{N} 2$ which included the retrofitting of this bridge. WBHO was the appointed contractor responsible for the construction of the first phase of this project, which included the widening of this bridge. Mott MacDonald Africa (Pty) Ltd, in a joint venture with Bosch Holdings were the consulting engineers appointed for the design and construction monitoring of the widening of this bridge.

\section{Concept Design}

The traffic study carried out for this section of road indicated that a single lane, bi-directional carriageway would provide sufficient capacity to meet the 20-year design horizon. The Client's primary reasons for widening this structure was to provide wider shoulders to make provision for two-way traffic flow in the event of vehicle breakdowns on the bridge and asphalt overlay of the road in the future as well as to upgrade the existing rail and post parapets with new F-shaped parapets. The existing bridge consisted of an average width of $12.08 \mathrm{~m}$ between the kerbs which comprised of two $3.7 \mathrm{~m}$ lanes and two $2.37 \mathrm{~m}$ shoulders. The widening of this structure was required to accommodate two $3.7 \mathrm{~m}$ traffic lanes and two $3 \mathrm{~m}$ wide shoulders equating to a $13.4 \mathrm{~m}$ clear width between the new F-shape parapets.

There were several constraints encountered whilst developing concept solutions for retrofitting this bridge. One such constraint was the lack of availability of as-built information of the existing bridge which made accurately calculating the load carrying capacity of the existing structure very difficult, without undertaking intrusive investigations. Another constraint was that the existing bridge superstructure was constructed on piers and abutments approximately $10.5 \mathrm{~m}$ above the river below which presented challenges relating to working at height. In addition, visible evidence of debris lodged at the top of the piers indicated that the flows in this major river were sometimes very high and thus there was a potential risk of flooding during construction. The potential costs and delays associated with the traffic accommodation requirements during the upgrade of this section of the National Route was another key consideration for this widening. The estimation of the allowable traffic loading on the existing bridge was a critical task in developing a solution to retrofit this bridge. To do so required a key assumption that the existing bridge would have been designed in accordance with the British Ministry of Transport

\footnotetext{
*Corresponding author: nerave30@gmail.com
} 
Loading (MoT) which was the prevailing code of practice for bridge design in South Africa up until the early 1970's. Based on this assumption, a reasonable estimate of the load carrying capacity was made.

Boreholes were drilled at ten (10) locations along the bridge to obtain the estimated bedrock depths to confirm the foundation levels of the existing bridge piers and abutments. The results indicated that hard sandstone rock was located at very shallow depths (less than $4 \mathrm{~m}$ ) from the riverbed level. Based on these findings it was assumed that the bridge was founded on spread footings on rock. The magnitude of the potential additional loads for the proposed widening were estimated and it was calculated that based on the available information and assumptions, the existing bridge foundations had sufficient capacity to support the widening. Therefore, no foundation or substructure widening was considered necessary which resulted in several benefits to the project which included financial savings due to reduced material costs, time related benefits to the construction process as well as reduced environmental impacts by reducing the construction work required within the watercourse.

Two proposals to retrofit the existing bridge were prepared and submitted to the Client for approval.

The first option (Option A) was to widen the existing superstructure on both the upstream and downstream edges (See Figure 01), which required the removal and reconstruction of the existing cantilever slabs on both edges of the bridge deck. During the design phase a section of the existing cantilever reinforcement was exposed to assess the area of existing reinforcement and estimate the capacity of the existing slab.

Based on the estimated additional load from the new widened cantilevers and the effect of impact loading on the new F-shaped parapets the existing cantilever reinforcement was found to be insufficient.
The solution to this was to strengthen the existing slab by grooving and epoxying additional reinforcement into the existing deck slab. A grillage model was generated to analyse the existing bridge deck for the estimated original traffic loading based on the British Ministry of Transport Loading (MoT) and the model was then expanded to analyse the effects of the proposed retrofitting of the existing bridge based on the current traffic loading requirements prescribed in the TMH7 code of practice (NA, NB36 and NC loading). This loading was applied to obtain the worstcase effects on the existing beams. It was assumed that the existing beams were designed to support the weight of the existing beam and slab superstructure, asphalt surfacing and the maximum effect of the traffic loading (MoT).

Where the bending moments and shear forces calculated exceeded the assumed capacity of the existing beams, external prestressing was proposed to strengthen the beams. From this exercise, it was determined that only the outer existing beams required strengthening.

Due to the lack of as-built information, a decision was taken to design new piles and ground beams behind both abutments to support new widened fill behind the abutments rather than increasing the size of the existing abutments to support the widened fill. The existing piers were estimated to have sufficient capacity to support the proposed widening. At the Client's request all the existing concrete hinge bearings were replaced with elastomeric bearings due to the failure of similar hinge bearings under seismic loading. The alternative proposal (Option B) was based on widening the bridge superstructure on the upstream side only (See Figure 01). The existing outer beams were assessed as described for Option A and found to have insufficient capacity to support the weight of the widened cantilever, the effects of the

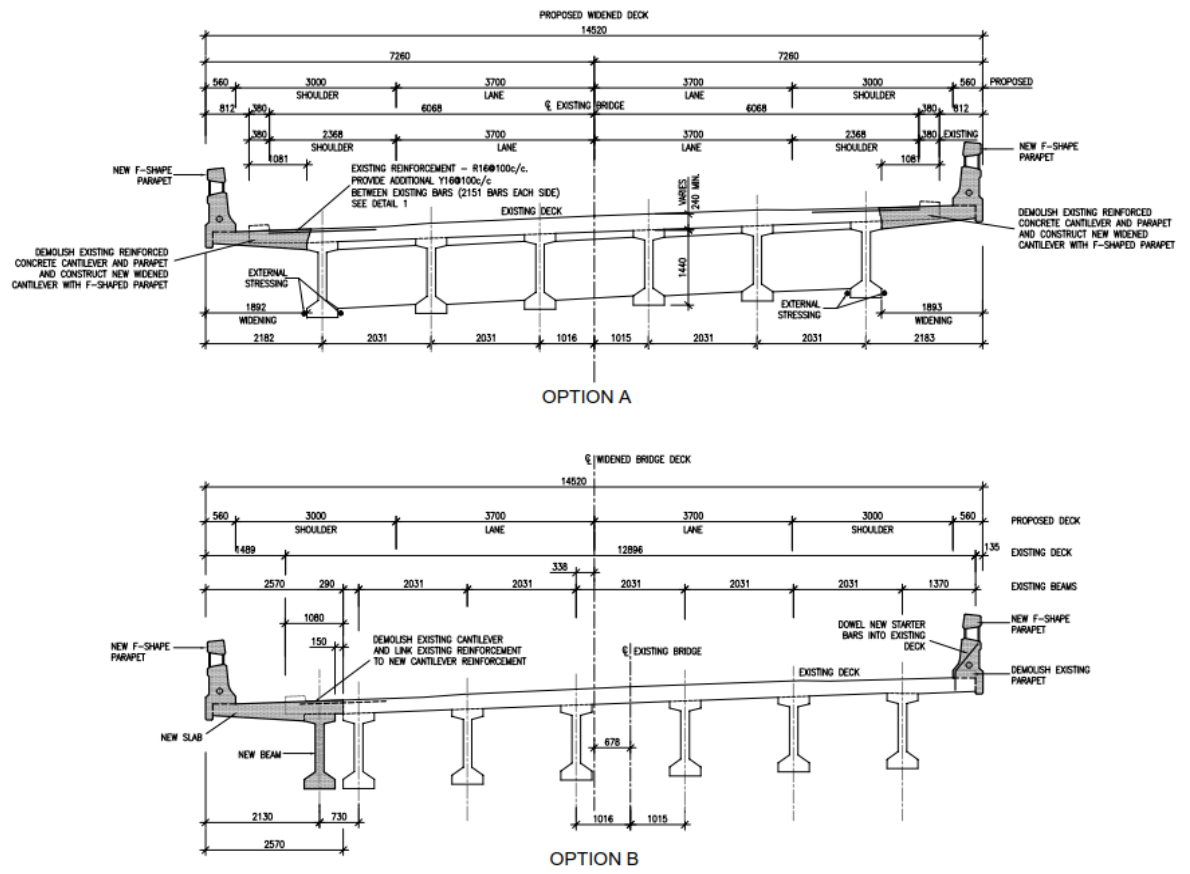

Figure 01 - Typical Cross Sections for Options A and B 
impact forces from the new parapets and the application of the current traffic loading for the widened superstructure configuration. The decision was made to design new precast beams to support the proposed widened cantilever.

Despite the availability of space on both the upstream and downstream side of the piers to accommodate a new beam it was decided to widen on the upstream side because of the additional out of balance force on the pier would act as a counter to the flood force effects. A portion of the existing upstream cantilever was demolished to provide a suitable connection with the existing slab and to provide sufficient space to install the new precast beams. On the downstream side, the only improvement required was to upgrade the existing rail and post parapets to new F-shaped parapets. The piers were also deemed to have sufficient capacity for this widening option and new approach slabs supported on new piles and ground beams as described for Option A was proposed. The existing bearing replacement was also included for this option. Cost estimates were prepared for both widening options and the estimated construction cost of Option B was found to be approximately $12.5 \%$ less than the construction cost for option A. The other benefits of Option B were the reduced disruption to traffic by restricting the major construction activities to primarily one side of the road, which presented further potential savings. On this basis Option B was recommended to and agreed with by the Client.

\section{Construction Challenges}

There were several practical challenges to execute the construction of Option B. These included jacking the existing bridge deck to remove and replace the existing bridge bearings under traffic loading; casting, stressing and erecting the new precast beams in confined spaces and supporting and casting the widened cantilever slab at heights of $10.5 \mathrm{~m}$ above the river without typical staging and formwork.

\subsection{Jacking and Existing Bearing Replacement}

One of the primary challenges for the Contractor was to safely jack up the bridge deck and remove and replace the existing bearings. To achieve this the Contractor had to develop a safe and effective temporary works proposal to support the hydraulic jacking equipment and the bridge superstructure under full traffic loading. Without as-built information of the superstructure the Engineer rejected the proposal to jack the superstructure from the existing diaphragm beams, which were assumed to have insufficient capacity to resist the stresses induced by the jacking forces. The Contractor's options were to support the hydraulic jacking equipment on $10.5 \mathrm{~m}$ high temporary works frames erected from the river bed below or from surface mounted supports attached to the existing piers and abutment walls. The Contractor decided to support the equipment from the existing piers and abutments and submitted a proposal to surface mount purpose made steel brackets onto the existing piers and abutment walls to support the jacking equipment (See Figures 02 \& 03).

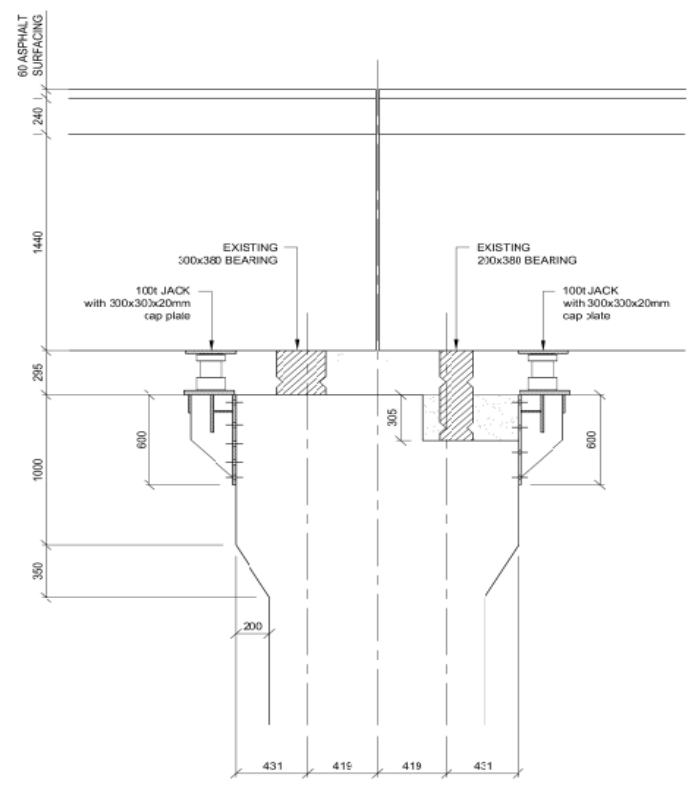

Figure 02 - Bracket-to-Pier Connection

Concrete core samples were taken from each existing pier and abutment wall to determine the compressive strength of the existing concrete, this information was used to calculate the required embedment depths and the pull-out resistance of the proposed bolts to connect these steel brackets to the existing concrete surfaces. The Engineer reviewed the Contractor's proposed steel brackets and the bolt sizes, quantity and embedment depths for the worstcase load combinations. The proposal was duly accepted and the subcontractor, iBhayi Contracting commenced with the installation of the brackets and the jacking equipment (See Figures 04 and 05). For access during the removal and replacement of the bearings the Contractor proposed a hanging access scaffolding system supported from the existing bridge deck. All existing joints were cleaned out before commencing with the jacking to prevent resistance to the lifts which could result in damage to the existing deck slabs. An additional restriction imposed on the Contractor was to ensure that both sides at any existing joint were jacked at the same time to minimise the disruption and inconvenience to the vehicles travelling over the bridge. 


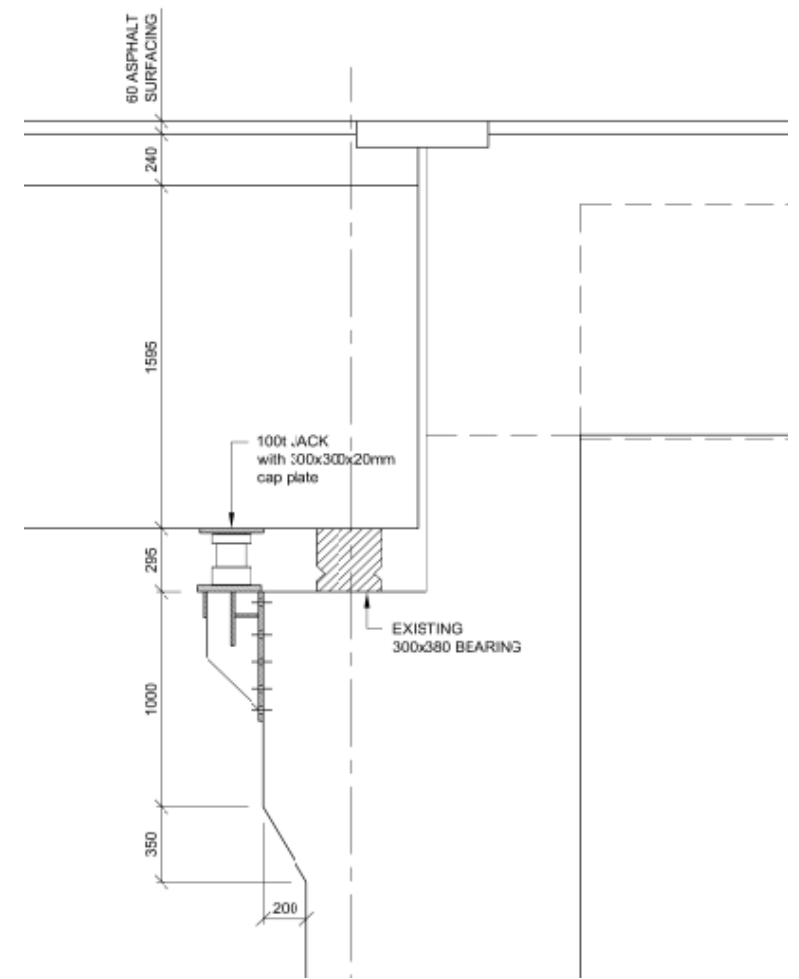

Figure 03 - Bracket-to-Abutment Connection

The Contractor planned to complete the replacement of all 108 existing bearings in 3.5 months and the task was ultimately completed in 4 months without incident. A lesson learnt by the team was to ensure that the existing joints were properly cleaned of debris and sealant and inspected before commencing the jacking, as in one case this was not done properly and an existing deck slab was cracked during the lift due to the restraint exerted by the adjacent slab. The crack had to then be repaired using an approved crack injection technique.

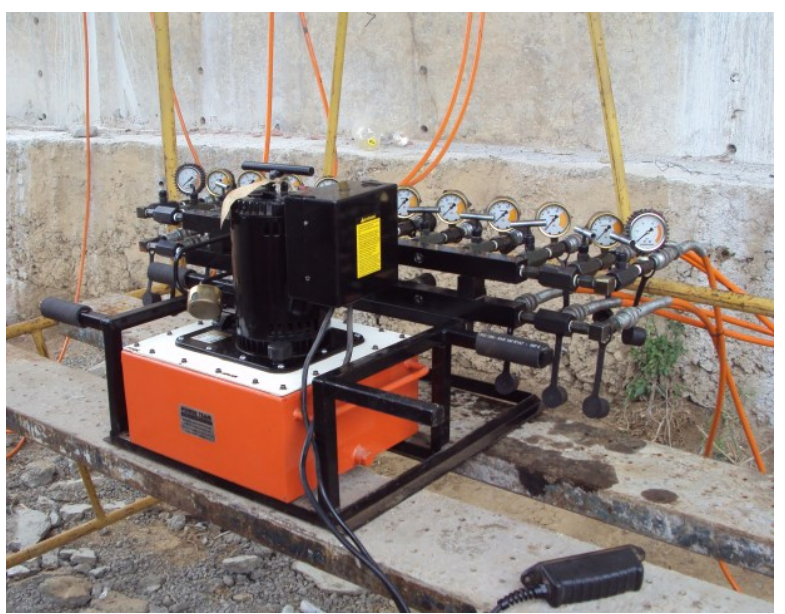

Figure 04 - Steel Brackets Supporting Jacking Equipment

The casting and stressing of the new beams was not dissimilar to the procedure followed for a new bridge construction. The Contractor setup a casting yard onsite to manufacture and stress the new precast beams. Theoretical concrete mix designs and prestressing arrangements were submitted by the Contractor for review and approval. A lesson learnt during the construction of the beams was that despite checking theoretical concrete mix designs, it is also important to consider the distance that the concrete will be transported from the batching plant to the site.

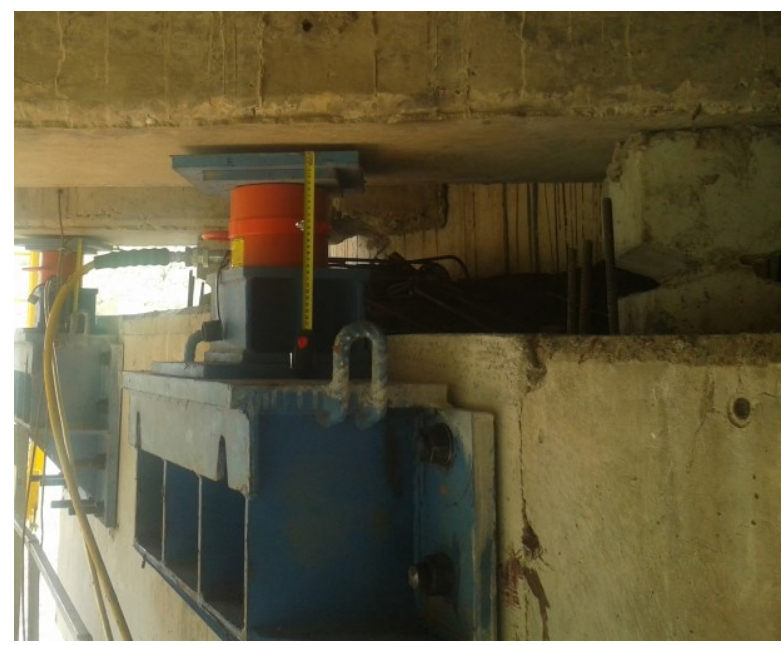

Figure 05 - Hydraulic Jacking Equipment

\subsection{Beam Manufacture and Erection}

When the concrete for the first precast beam was batched the supplier added an increased amount of admixture in the mix to maintain the workability of the concrete during the 3-hour journey to deliver the ready mixed concrete to site. This may have been done without adjusting the proportions of the other constituents in the theoretical mix design and thus despite achieving suitable workability, the concrete did not gain the required 28-day strength. Concrete coring and Schmidt Hammer testing was performed but the results indicated that the required concrete compressive strength was not achieved and the beam was rejected. The concrete mix was modified for the manufacture of the remaining beams which achieved both the required strength and durability properties. The prestressing of the beams was expertly carried out with the scheduled duration for casting and stressing the beams programmed for 4.5 months and ultimately completed by the Contractor in 5 months.

The erection of the new precast beams for the superstructure widening was a difficult practical challenge. At the tender stage, the Contractor submitted a proposal and methodology for the erection of the new 32.5-ton precast beams onto the $10.5 \mathrm{~m}$ high existing piers and abutments walls. The proposal outlined the procedure for transporting the beams from the casting yard to the lifting positions, the method and equipment required for lifting and placing the beams, the quality control procedures, the potential safety risks and mitigation measures, and the potential delays and impacts on traffic and the associated traffic accommodation proposals. The Contractor's proposal was to construct a temporary causeway on the upstream side of the river bed, outside of the rainy season, to provide access for a 200-ton crane to be 


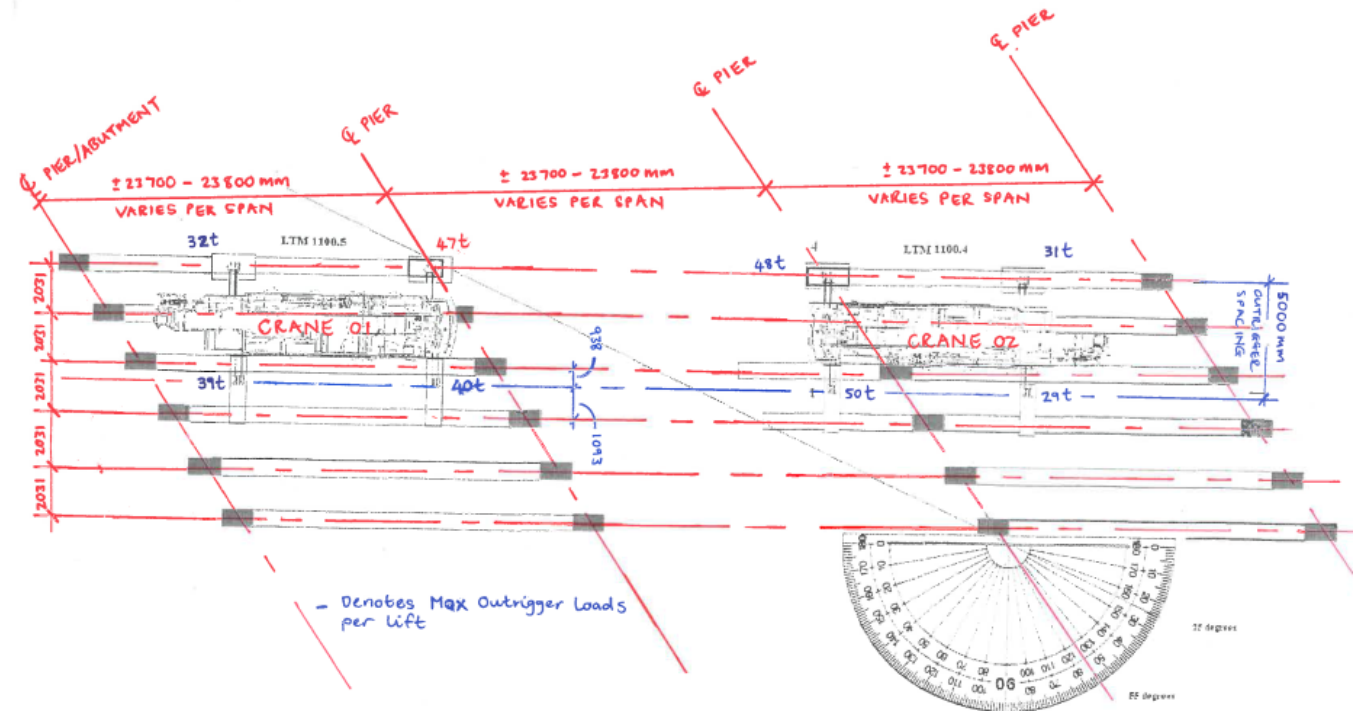

Figure 06 -Superimposed Crane Footprint on Existing Beam Configuration

positioned to lift 6 of the 9 beams into position from below. Temporary access roads and ramps were proposed to allow a $50 \mathrm{~m}$ long heavy-duty vehicle to transport the $24 \mathrm{~m}$ long beams from the casting yard to the lifting positions. For the remaining three (3) spans over the flowing river the Contractor proposed using the 200-ton crane on the existing bridge deck, at positions deemed safe by the Engineer.

The Contractor estimated the erection of the nine (9) new beams to be a three-day process and indicated that throughout these activities one-way traffic would be accommodated apart from three short one-hour long road closures during the transportation and erection of the three beams by the 200t crane positioned on the existing bridge deck. The Contractor proposed a stop and go system to manage this process. After the Contractor was appointed, the Engineer requested detailed information for the proposal including details of the crane size, rigging studies with outrigger loads per lift and a more detailed hourly timeline for the activities to verify if the three-day duration was achievable. The 200t crane footprint was superimposed on the existing bridge deck and it was evident that there was insufficient space (less than $3 \mathrm{~m}$ ) for one-way traffic to pass while the crane was on the bridge, which would result in complete closure of the route for longer durations per lift to allow for the time to setup and position the crane. The Contractor was instructed to provide a revised proposal which would minimise the duration of the road closures.

The revised proposal involved tandem lifting the four (4) new beams from on top of the existing bridge deck using two smaller 90t and 110t cranes. Based on the flow path of the river and accessibility for the cranes from below the N2, it was decided that the Contractor would erect the first five (5) beams from below using a 250-ton crane and the remaining four (4) beams from above using the tandem lift. The crane footprint and outrigger positions were superimposed onto the existing deck beam positions to ensure that the crane loads were carried on the existing beams only (See Figure 06). No loads were imposed on the existing deck slabs.

The outrigger loads for the tandem lift option (up to $48 \mathrm{t}$ ) were lower than the loads from the initial proposal of using one $200 \mathrm{t}$ crane (up to $78 \mathrm{t}$ ) on the bridge deck due to the beam weight during the lift being shared between the two cranes. Despite this reduction, the outrigger loads for the tandem lift still equated to pressures greater than the maximum allowable pressure of $1.1 \mathrm{~N} / \mathrm{mm}^{2}$ prescribed in TMH7. The spacing of the outriggers of these smaller $90 \mathrm{t}$ and $110 t$ cranes did not overlap with the spacing of the existing beams and the Contractor was instructed to design and supply spreader beams that spanned between two existing deck beams to support the outriggers and distribute the loads onto the existing deck beams. This avoided the risk of punching failure due to the application of these high concentrated loads onto the existing deck slab. The Contractor submitted a design and drawings for these steel spreader beams to the Consultant for approval (See Figures 07 and 08).

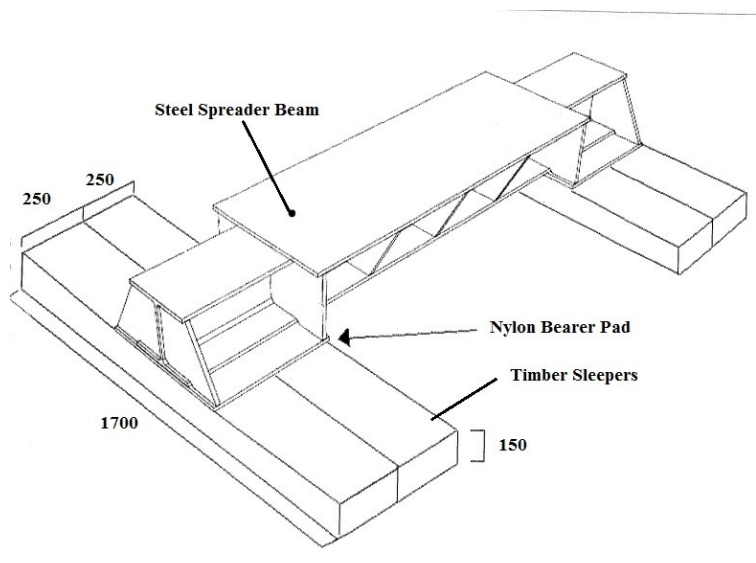

Figure 07 - Spreader Beam Isometric Drawing 


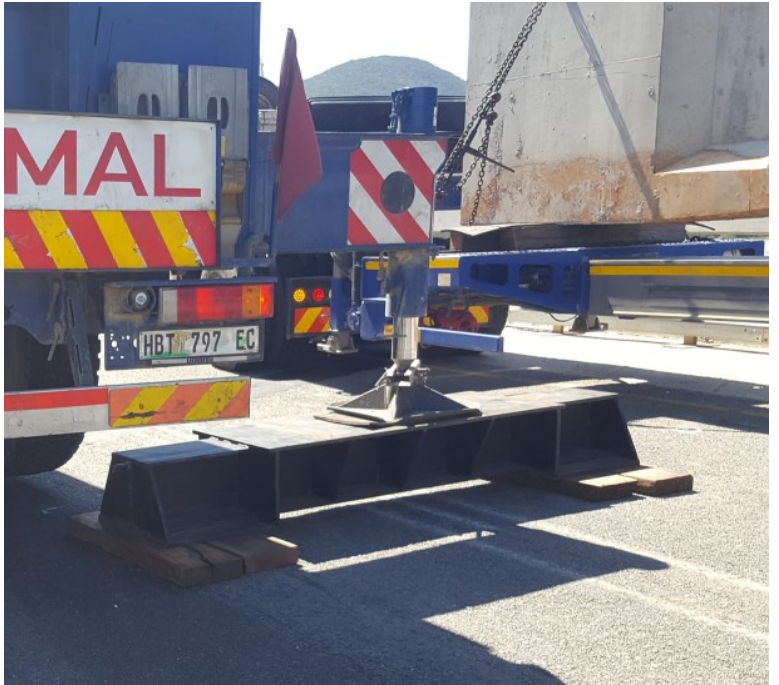

Figure 08 - Steel Spreader Beams During Tandem Lift

To determine the maximum permissible outrigger loads for the tandem lift, it was assumed that no traffic would be permitted on the bridge during the lift. From the detailed design calculations for the bridge widening, the proportion of bending and shear capacity of the existing beams due to the traffic loading (MoT) only, equated to $3786 \mathrm{kNm}$ and $650 \mathrm{kN}$ for the outer beams and $3407 \mathrm{kNm}$ and $596 \mathrm{kN}$ for the inner beams. An additional 10\% reduction to these values was applied as an added factor of safety to further limit the permissible outrigger loads. These reduced allowable bending moments and shear forces in the existing beams were then used as the limits to determine the maximum allowable outrigger loads at each outrigger position during the tandem lifts. Where the outrigger loads were near these bending and/or shear capacity limits, the crane positions were adjusted longitudinally by either moving the positions further away from midspan to reduce the bending moment effects or further from the bridge supports to reduce the shear force effects until a suitable position was found which was within these limiting capacities. The outer beams had higher estimated capacities than the inner beams which was further improved by the beneficial reduction in dead load from the partial demolition of the existing outer cantilever slab. It was therefore decided that two outriggers would be positioned directly over the outer existing beams, whilst the other two outriggers would be supported on the spreader beams to distribute their loads between two existing inner deck beams. It was also decided that railway sleepers would be used to elevate the spreader beam above the road surface to ensure that under load there was sufficient space for the beams to deflect and to provide a larger distribution area onto the existing bridge beams for the loads from the outriggers. The properties of the saligna timber railway sleepers were obtained to check that they could distribute these high loads from the crane outriggers safely. Finally, the capacity of the lifting hooks, slings, shackles and other components used to execute the lift were checked to ensure that these could all perform at the required loads during the lift.

The Contractor was asked to outline the quality control procedures that would be employed to ensure that the approved outrigger positions for each lift were correctly set-out and monitored and to ensure that the loads at each outrigger were monitored against the maximum limits prescribed in the approved rigging studies. During the erection process, the subcontractor Castle Crane Hire, marked-out the positions of the spreaders and outriggers onto the road surface using paint markings for each of the four lifts which were checked and signed off by the Contractor and the Engineer before commencing with the lift (See Figure 09). Another challenge encountered during the lifts was the high wind speeds and based on the experience of the subcontractor a decision was taken to check the wind speeds before each lift to ensure that no lift was executed at speeds greater than $35 \mathrm{~km} / \mathrm{h}$. All four beams were erected without incident.

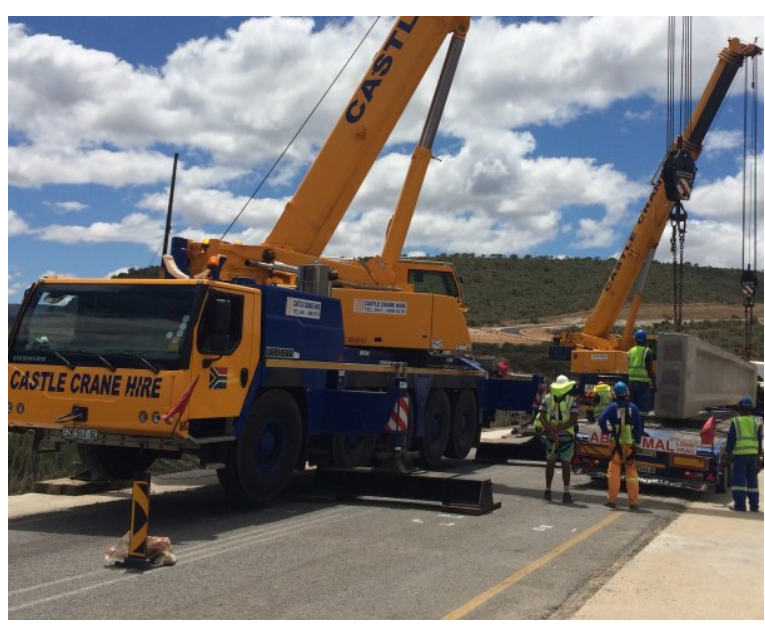

Figure 09 - Tandem Lift

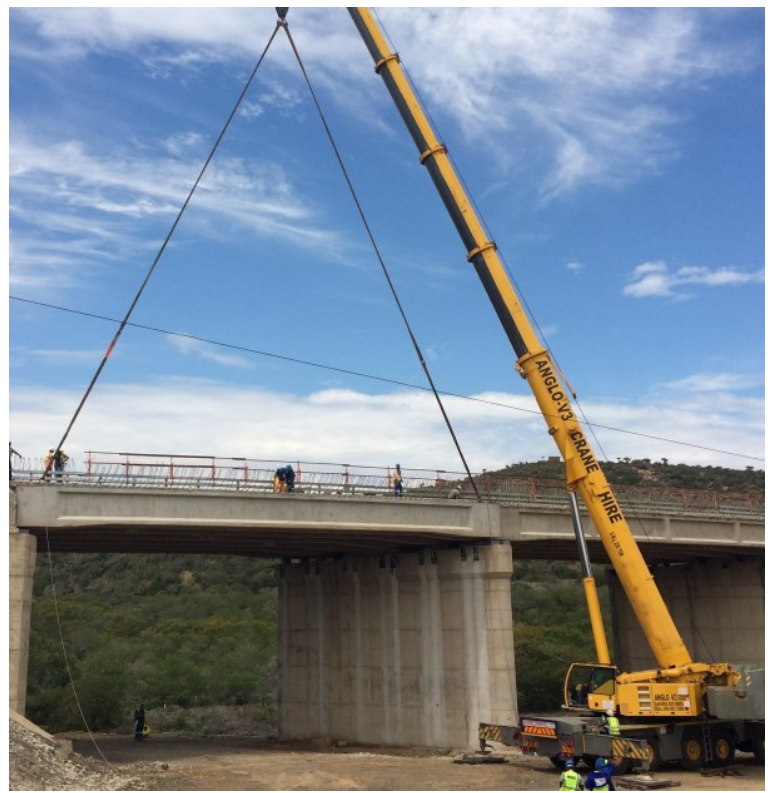

Figure 10 - Riverbed Lift 
The proposal for the erection of the five (5) beams from below the existing bridge was less of a risk than the tandem lift. The Contractor prepared a level, compacted earthworks platform on the upstream side of the river from which the proposed 250t crane would execute the beam lifts (See Figure 10). The estimated maximum load per outrigger for the $10.5 \mathrm{~m}$ high lift based on the rigging studies was $78 \mathrm{t}$ and thus settlement of the earthworks platform under these loads during the lifts was a concern. The Contractor was instructed to undertake Dynamic Cone Penetrometer (DCP) tests at each of the proposed outrigger positions for each of the lifts to determine a reasonable assumed allowable bearing capacity at each position. Based on the maximum expected load of $78 \mathrm{t}$ at an individual outrigger and the $600 \mathrm{~mm}^{2}$ outrigger pad area, the estimated pressure on the ground was calculated to be $625 \mathrm{kPa}$. From the geotechnical information available, the hard sandstone for the foundations was at shallow depths below platform and could safely handle pressures this high and thus the primary concern was with the level of compaction of the upper layers of the Contractor's earthworks platform. A lesson learnt was to ensure that the ground is suitably compacted at the outrigger positions as one outrigger was in a position that wasn't suitably compacted during the last of the five lifts and when the crane took the weight of the beam as it was lifted off the transport vehicle, the ground below the outrigger settled. Fortunately, this occurred whilst lifting the beam off the transport vehicle, so the beam was placed back onto the truck before relocating the crane to a safer position to complete the lift.

\section{Conclusion}

Despite the complicated practical challenges that accompanied the retrofitting of this existing bridge, there were several time related, financial and sustainable benefits to retrofitting this existing structure. The primary financial benefit was achieving the superstructure widening without having to widen the substructure which had proven savings in material costs as well as time related savings due to the reduced construction period. The reduced environmental impacts of this option would also have resulted in reduced environmental management planning costs and measures. The erection of five (5) of the new beams from below the N2 resulted in fewer road closures, less impact to the daily traffic and shorter durations for the stop and go traffic accommodation, which would also have resulted in reduced financial costs to the project. The total cost of retrofitting this existing bridge inclusive of all ancillary works and repairs to the existing structure amounted to approximately ZAR $14.5 \mathrm{mil}$ which equated to approximately ZAR 22907 per $\mathrm{m}^{2}$ of the widened bridge. 